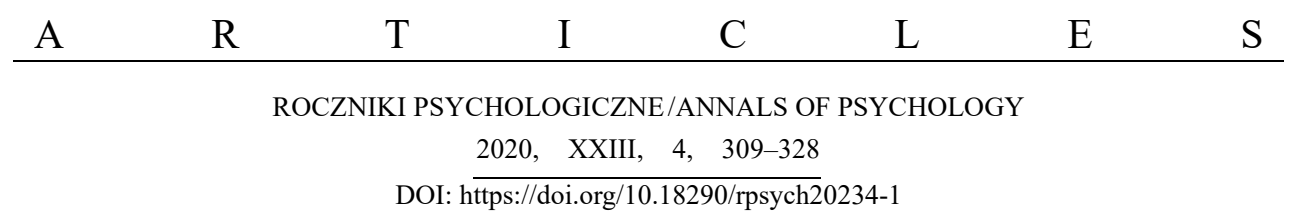

TOMASZ JANKOWSKI

WACŁAW BĄK

John Paul II Catholic University of Lublin

\title{
IN SEARCH FOR THE ADAPTIVE SELF: A MODEL OF ADAPTIVE SELF-CONCEPT
}

\begin{abstract}
The main aim of this article is to present a descriptive social-cognitive model of the adaptive self-concept (ASC) which integrates knowledge concerning the relationship between two aspects of the self-self-awareness and self-knowledge - and optimal functioning. We propose that adaptive self-awareness is moderately frequent, non-ruminative, focused on inner states, and motivated by curiosity. Adaptive self-knowledge is defined as accurate, complex, integrated and consisting of easily accessible self-beliefs, both abstract and concrete. The broader context for the ASC model is discussed, including its regulatory and interpersonal functions and factors which influence ASC development. The limitations of the model are discussed and suggestions are made for future investigations.
\end{abstract}

Keywords: adaptive self; self-concept; self-knowledge; self-awareness; quiet ego.

Contemporary psychology considers adaptation to the social environment as one of the most essential functions of the self. From an evolutionary point of view, the development of a unique mental apparatus - the symbolic self-has allowed humans to adapt much more extensively to specific environments (Sedikides \& Skowronski, 1997). The ability to treat oneself as an object of cognition and evaluation enables individuals to construct a cognitive model of their self. It facilitates regulating one's behavior, achieving long-term goals, taking

Correspondence concerning this article can be sent to TOMASZ JANKOWSKI, PhD, Institute of Psychology, The John Paul II Catholic University of Lublin, Al. Racławickie 14, 20-950 Lublin, Poland; e-mail: tomasz.jankowski@kul.pl; ORCID: https://orcid.org/0000-0002-0636-3051; WACŁAW BĄK, PhD, ORCID: https://orcid.org/0000-0001-8629-6292.

Funding Information: This research was supported by a grant from the National Science Centre (NSC; 2015/19/B/HS6/02216). 
the perspective of others and communicating via symbolic or abstract language. Yet despite these potential benefits, it is difficult to define to what extent a given individual benefits from having a symbolic self.

Recently, the question of what it means to have an adaptive self has been raised by proponents of positive psychology (e.g., Brown \& Holt, 2011) and this has prompted new theoretical investigations, for example, the concept of the quiet ego (Wayment et al., 2014). However, there is a need for research integrating the vast amount of social and cognitive psychological studies on the self with new ideas grounded in positive psychology. The main aim of this article is to distinguish and describe the aspects of adaptive self-concept. The adaptive self-concept is an "umbrella construct" by which we mean these characteristics of the self-concept that are predictors of optimal functioning. We start with a review of the state of research on the self-concept, which is intended to identify those characteristics which are critical to effective adaptation. Drawing on this analysis, we propose a descriptive model of what we have termed adaptive self-concept (ASC).

\section{FEATURES OF THE ADAPTIVE SELF}

To organize our review of the literature, we followed Leary and Tangney's (2012) proposal to distinguish between three basic aspects of the self: self-awareness, self-knowledge, and self-regulation. Self-awareness depends on attentional processes and refers to the capacity to become the object of one's own attentional processes. Self-knowledge requires higher cognitive processes such as imagining and refers to the structured contents of self-concept and identity. Finally, self-regulation relates to executive processes and refers to the ability to direct and monitor behavior to achieve self-imposed goals. Based on this distinction, we were able to identify both processual (i.e., related to self-awareness) and structural (i.e., related to self-knowledge) aspects of ASC. We assumed that self-knowledge and self-awareness are mutually dependent. In other words, the way one thinks about oneself (e.g., rumination) can result in structural features of self-knowledge (e.g., low self-concept clarity). However, the quality of self-knowledge (e.g., low self-concept clarity) can also trigger the particular modes of thinking about the self (e.g., rumination). Thus, the relationship be-tween self-awareness and self-knowledge can operate in terms of feedback loops. Moreover, we assumed that the ability to efficiently self-regulate is mainly the effect of adaptive self-awareness and self-beliefs; thus we did not 
include effective self-regulation as the core ASC dimension but rather treated this phenomenon as the effect of the ASC.

\section{Self-Awareness and Adaptation}

A review of the literature revealed that although self-awareness is based on simple attentional processes, it is a complex, multidimensional phenomenon. It may be considered either as a transient state or as a relatively stable personality disposition (Fenigstein et al., 1975; Silvia \& Duval, 2001). In both interpretations, self-focused attention may relate to several different aspects of the self and thus be private or public (Fenigstein, 2009).

One needs to consider the complex nature of self-awareness if one wants to analyze the relationship between self-awareness and well-being. Otherwise, it will be difficult to understand why self-awareness can both enhance and diminish human functioning. The vast majority of empirical research suggests that high self-awareness is negatively related to psychological functioning. Pyszczynski and Greenberg (1987) proposed a model of depression in which self-absorption plays a critical role in a pathological process. Ingram (1990) drew even more general conclusion, stating that elevated levels of self-focused attention were a common factor in the majority of mental disorders. Similarly, a meta-analysis by Mor and Winquist (2002) revealed a moderate positive correlation between self-awareness and negative mood. Nevertheless, some degree of self-awareness is essential to effective functioning; without self-awareness it would be impossible to take the perspective of someone else, to create new ideas, to aspire to and achieve goals or to experience pride and satisfaction. Self-awareness seems to be fundamental to many uniquely human capabilities (Silvia \& O'Brien, 2004).

The positive aspects of self-awareness can be easily and intuitively understood, but it is perhaps more difficult to understand how and why self-awareness can also have detrimental effects. Duval and Wicklund's (1972) objective self-awareness theory offered one of the first explanations. It states that self-awareness induces self-evaluation: in a state of objective self-awareness an individual automatically compares his or her actual self with some relevant standard. In most cases this comparison reveals a significant discrepancy between the actual self and the standard and thus induces negative affect; the more often an individual focuses on his or her self, the more frequently he or she experiences negative affect. This is especially true for individuals who compare themselves with a hard-to-attain standard (Silvia \& O'Brien, 2004). Duval and 
Wicklund (1972) claimed that because self-awareness entails self-evaluation, it is an aversive state. It has also been proposed that individuals frequently engage in various destructive behaviors to avoid this aversive state (Baumeister, 1991). Research has confirmed that self-absorption (a form of intense self-awareness) is related to the intensity of maladaptive symptoms (McKenzie \& Hoyle, 2008).

In line with this, Burnkrant and Page (1984) distinguished between self-reflection and awareness of one's internal states. Self-reflection involves using higher cognitive processes to analyze and evaluate the self. In contrast, awareness of one's internal state is simply the awareness of one's current emotional and cognitive processes. Several studies have shown that self-reflection is correlated with poor psychological functioning (confirming Duval and Wicklund's hypothesis), whilst awareness of internal states is positively correlated with well-being (Creed \& Funder, 1998). Still, awareness of one's internal states is not sufficient to support a comprehensive self-concept.

Acquisition of self-knowledge depends on higher mental processes such as reflection and analysis. Self-knowledge is more than just a collection of self-related events; it is rather one's theory about oneself. Trapnell and Campbell (1999; see also Silvia et al., 2005) distinguished two basic types of motives underlying deep processing of self-relevant information. The first is related to anxiety and uncertainty about the self. When an individual reflects on his or her self in an attempt to reduce self-related negative emotions, the outcome is almost always negative (Lyubomirsky \& Tkach, 2003). The second type of motivation is based on self-directed curiosity. When thinking about oneself is motivated by curiosity, it takes a philosophical, explanatory form and facilitates personal growth and subjective happiness (Harrington \& Loffredo, 2011).

To summarize, adaptively self-aware individuals have enhanced awareness of their internal states, and their self-reflection is mostly motivated by curiosity. They also have an optimal level of dispositional self-consciousness-high enough to support other important capabilities, but not as high as to result in self-absorption.

\section{Self-Knowledge and Adaptation}

Having the ability to focus attention and reflect on oneself enables the construction of self-knowledge. It involves the formulation of beliefs about oneself that influence one's subsequent behavior in a given environment. The content of self-knowledge is unique to the individual; however, it has some formal 
characteristics that can be related to adjustment. In our analysis of how the structure of self-knowledge relates to psychological adaptation, we focus on three issues: (1) the extent to which self-beliefs are congruent with objective data, (2) the concrete vs abstract nature of self-representations, and (3) the structure of self-knowledge defined in terms of its differentiation and integration.

\section{Accuracy of Self-Knowledge}

How closely should self-beliefs correspond to objective data if self-knowledge is to be useful and adaptive? Following Kernis and Goldman (2006), we propose that accurate and realistic self-knowledge fosters adaptation. The model of realistic self-knowledge posits that successful adaptation requires a fair degree of correspondence between one's self-concept and the relevant external data (e.g., one's behavior or feedback from significant others). This approach follows a long philosophical tradition dating back to Socrates and is strongly supported by empirical research (e.g., Colvin et al., 1995; Robins \& Beer, 2001).

Acquiring self-knowledge which is congruent with both inner experience and outer behavior requires unbiased processing of self-relevant information (Kernis \& Goldman, 2006). Several studies have shown that there is individual variation in the degree to which self-perceptions are biased. Knee and Zuckerman (1998) showed that high dispositional intrinsic motivation is associated with low levels of defensiveness. Similarly, experiments by Hodgins et al. (2006) showed that participants primed to act autonomously were less defensive on an anagram task than those primed to act in a controlled, impersonal way, that is, they reported lower levels of desire to escape, self-serving bias and self-handicapping. In a series of further studies (Hodgins et al., 2010), the authors showed that this effect was mediated by threat response in the situation of social exposition. This suggests that intrinsic motivation reduces anxiety and thereby decreases the tendency to behave defensively.

Another interesting line of research explores the idea that using mindfulness techniques can reduce self-serving defensiveness and thereby improves the accuracy of self-knowledge. Mindfulness is defined as the ability to focus one's attention on the present. Niemiec et al. (2010) demonstrated that high dispositional mindfulness is associated with attenuated defensive responses in circumstances where mortality is highly salient. Individuals with a high disposition to be attentive to ongoing experience and receptive to environmental data reported fewer defensive worldviews and exhibited a lower desire for self-esteem under the con- 
dition in which mortality was made salient. They also spent a longer time writing about their visualized death and did not suppress thoughts about death to the same extent as people low in mindfulness. Both dispositional and situationally induced mindfulness is associated with reduced self-reported aggressiveness and hostile attribution bias and to a less aggressive response to social rejection (Heppner et al., 2008). Similarly, mindfulness has been shown to mediate the negative relationship between authenticity and verbal defensiveness (Lakey et al., 2008).

Two additional issues should be mentioned at this point. First, having accurate self-knowledge does not necessarily mean that it is representative in terms of the proportions of positive and negative self-descriptions (Colvin \& Block, 1994). Developmental processes usually lead to experience oneself as a competent and autonomous person, which results in a predominance of positive self-representations (Ryan \& Brown, 2003). This is not to suggest that an over-representation of positive self-descriptions is characteristic of an individual who is deluded about his or her real capabilities, rather it is considered a characteristic of accurate self-knowledge of a well-functioning individual. The second issue relates to the concept of positive illusions (Taylor \& Brown, 1988). There are convincing arguments that humans have evolved to have positively biased self-perceptions. Consequently, some degree of positive yet inaccurate self-beliefs should be regarded as typical of a healthy self (McKay \& Dennet, 2009). Although having an accurate self-concept can facilitate the achievement of long-term goals, positive self-illusions are adaptive in the short run, as a way of coping with negative emotions and enhancing positive mood (Crocker, 2002; Robins \& Beer, 2001). In most cases, distorted self-perceptions arise automatically and unintentionally (Bargh \& Chartrand, 1999).

Taking these into consideration allows us to refine our earlier statement about the adaptive qualities of the self. People with adaptive self-concept, that is, one which supports effective psychological functioning, are both positive and realistic in their self-knowledge; at the same time, however, they are prone to deeply rooted, automatic distortions of self-perceptions. Adaptive self may thus depend on the additional capability that Brycz and Karasiewicz (2011) have termed the metacognitive self. Realistic and accurate self-knowledge does not reflect an absence of self-illusions; rather, it lies in the ability to recognize biases in one's self-perception. Brycz and Karasiewicz (2011) showed that there is individual variation in the abilities which make up the metacognitive self and that being aware of distortions in one's self-perceptions facilitates self-regulation. 


\section{Concrete and Abstract Self-Definitions}

Self-knowledge is organized hierarchically, with more general or more abstract self-definitions at the top of the hierarchy (Conway, 2005; McConnell, 2011). Although there are situational fluctuations in the degree of abstraction of self-definitions, more stable individual differences can also be observed (Vallacher \& Wegner, 1989). The important issue is whether the degree of abstraction of self-knowledge is related to well-being; in other words, whether it is more adaptive to conceptualize one's self in concrete or more abstract terms.

This issue was addressed by Leary et al. $(2006,2010)$ in their theory of hypoegoic self-regulation, saying that concrete self-definitions are more adaptive in the context of everyday self-regulation. Similarly, Freitas et al. (2004) argued that a narrow, concrete mindset that considers "how" rather than "why" one behaves is of greater adaptive value. A related idea was formalized as Action Identification Theory (AIT; Wegner \& Vallacher, 1986). AIT posited that action identification should be as concrete as possible in any given situation to avoid identity inflation, a state in which the individual focuses on excessively high-level goals. Leary et al. (2010) argued along similar lines, that concrete self-knowledge was advantageous when connected with implementing intentions (Gollwitzer, 1999).

We do not consider the arguments put forward by Leary et al. $(2006,2010)$ as sufficient to conclude that abstract self-definitions are useless or maladaptive. Moreover, empirical data indicates that abstract self-knowledge plays an important role in self-regulation. From an evolutionary point of view there are at least three adaptive functions of abstract self-descriptions (Klein et al., 2002): (1) interpretation of new situations and integration of new information about the self (Förster et al., 2010); (2) prediction of one's behavior in addition to the behavior of others (Swann et al., 1992), and (3) the ability to make fast, automatic decisions in social situations (Wegner \& Bargh, 1998). Thinking about the self in broad, general terms allows the individual to transcend the here and now and view their current self from a different perspective (Wakslak et al., 2008).

The above two lines of reasoning emphasizing adaptive usefulness of concrete versus abstract self-representations seem somewhat contradictory, but they can be rather viewed as complementary. We believe that both abstract (contextfree) and concrete (context-dependent) ways of thinking about the self can be adaptive. Effective self-regulation seems to depend not on preferential use of concrete self-knowledge, but on the ability to activate the various levels of self-representation flexibly and adequately to the context. This is in line with 
novelty categorization theory (Förster et al., 2010) which states that when faced with novelty, an individual activates global perceptual processes to grasp the general meaning of the situation. Subsequently, if the individual is motivated to learn more about the situation, he or she will switch to local processing mode to gain access to more detailed information. The benefits of flexible self-regulation were also demonstrated by Klein et al. (2002). Based on research on semantic and episodic self-knowledge, these authors concluded that in any given situation, the most effective approach is to activate a general self-attribute and simultaneously recall episodic memories that are inconsistent with this attribute. These concrete, inconsistent memories "place boundary conditions on the scope of the generalization" (Klein et al., 2002, p. 306) and thus inhibit identity inflation and improve decision making. The adaptive value of flexibility was also emphasized in AIT (Vallacher \& Wegner, 1987), according to which the degree of abstraction of the optimal level of action identification depends on perceived task difficulty, i.e. its complexity, familiarity and how much time it is likely to require (Vallacher \& Wegner, 1989). As task difficulty increases the level of action identification should decrease. However, in the case of simple, routine tasks, higher levels of processing should be engaged to align task performance with more general and meaningful goals.

Whilst cognitive flexibility has adaptive value, an inflexible tendency to construct abstract or concrete self-representations may be detrimental to adjustment. Vallacher and Wegner (1989) suggested that personally important situations involving competition, audience evaluation or social pressure, may trigger excessive self-identification, leading to identity inflation and reduced performance. Likewise, novelty categorization theory (Förster et al., 2010) predicts that dealing with novelty in the context of high levels of anxiety is likely to result in a maladaptive fixation on details; however if the initial global processing of novelties is not followed by more detailed investigation it may lead to stereotyping. Narrative studies investigating the phenomenon of over-general autobiographical memory have shown that difficulty in retrieving specific memories and recall limited to categorical memories (autobiographical summaries) are associated with lower levels of psychological functioning (Williams et al., 2007) and are an important risk factor for depression and post-traumatic stress disorder (Moore \& Zoellner, 2007; Sumner et al., 2011).

It seems that neither exclusively abstract nor exclusively concrete representations of self-relevant information are adaptive. It is the ability to access either specific or general representations flexibly, which seems to be crucial to 
well-being and effective self-regulation. Malleable use of self-representations also seems to relate to self-complexity and self-coherence-structural aspects of self-knowledge which are considered in the next section.

\section{Self-Complexity and Self-Coherence}

Psychological adjustment depends on the structure as well as the content of self-knowledge. To understand the relationship between the structure of self-knowledge and well-being we need to consider its two main structural variables, unity and complexity of self-concept, which are independent and contribute differently to adaptation (e.g., Campbell et al., 2003).

There are many definitions of unity in the context of self-concepts. It may be understood as "sameness and continuity" and related to the sense of self (Block, 1961, p. 392); as a "tendency to see oneself as having 'the same' personality characteristics across one's roles" (Donahue et al., 1993, p. 834); as a reflection of the degree to which one's self-representations are certain, temporally stable and internally consistent (Campbell et al., 1996); as a measure of similarity between self-standards and actual self (Higgins, 1987); as the degree of correspondence between first- and third-person perspectives on the self (Campbell et al., 2003) or as a tendency to include both positive and negative information in a single self-representation (Showers et al., 1998).

Many studies have shown that self-concept unity is positively associated with various indicators of psychological adjustment (e.g. Campbell et al., 2003; Diehl et al., 2001; Donahue et al., 1993; Ferguson et al., 2010; Higgins, 1987; Showers \& Zeigler-Hill, 2007). Although results are convergent in terms of the direction of the association, effect sizes seem to be moderated by the method used to measure unity. The sense of inner clarity measured by the Self-Concept Clarity Scale (Campbell et al., 1996) explained a much greater proportion of the variance in psychological adjustment than a self-concept differentiation index, based on structural analysis of participants' self-concepts (Bigler et al., 2001). Similarly, although both a subjective indicator of inner integration (sense of authenticity) and an index of implicit self-differentiation were significantly associated with well-being, the strength of the association was greater in the case of the former indicator (Sheldon, et al., 1997).

Self-complexity is another important structural variable. It is usually defined as being a function of the number of categories (e.g., social roles) into which an individual can organize self-knowledge and the degree to which these categories 
are related; the more unrelated categories, the higher the self-complexity (Linville, 1987; Showers \& Zeigler-Hill, 2012). Although many studies have investigated the relationship between self-complexity and psychological adjustment, the results remain inconclusive. Linville's seminal research $(1985,1987)$, which suggested that self-complexity was a stress-buffering factor, has proved difficult to replicate (for reviews see Koch \& Shepperd, 2004; Rafaeli-Mor \& Steinberg, 2002). Campbell et al. (2003) found no significant direct relationship between self-complexity and well-being, a result which is consistent with a meta-analysis showing no correlation, or a moderate negative correlation, between self-complexity and various indicators of psychological adjustment (Rafaeli-Mor \& Steinberg, 2002).

Several explanations, both theoretical and methodological, have been offered for the inconsistent findings on the relationship between self-complexity and well-being. Here we focus on one, the conceptual ambiguity of the self-complexity construct. Although the prefix "self" indicates that the term refers to complexity related to the individual subject rather than to the environment, it is unclear whether instruments which purport to measure self-complexity quantify an inner disposition to see the world and oneself as complex or to the extent to which the subject conforms to various expectations of the complex, social environment in which he or she lives. The difference between dispositional (self-derived) self-complexity and reactive (environmentally or socially induced) self-complexity may account for the inconsistent findings of research on self-complexity. If high self-complexity reflects a mindfulness disposition, that is, openness to novelty and willingness to draw novel distinctions (Langer \& Moldoveanu, 2000), it may facilitate adaptation to novel situations and different social roles, and thus enhance well-being (see Langer, 1989). If, however, high self-complexity is mainly a product of a tendency to conform to expected social roles it may be an indicator of self-fragmentation and thence be associated with poor adjustment (Lutz \& Ross, 2003; Oppenheimer, 2002).

To sum up, we postulate that psychological adjustment is (a) more strongly associated with perceived inner unity than the degree of structural integration of one's self-representations; (b) positively associated with self-complexity, given that this is defined as the number of described in details and contextually nuanced self-categories; and (c) strongly associated with integrative complexity (see McAdams et al., 2004; Suedfeld, 2009), which refers to both differentiation of self-knowledge and the sense of being a single, coherent, continuous person regardless of social or occupational context. 


\section{ADAPTIVE SELF-CONCEPT}

A review of studies of the relationship between the self and psychological adjustment suggests that several characteristics facilitate well-being and have adaptive value. We aimed at synthesizing this knowledge into a descriptive model of adaptive aspects of self-concept and put it into the broader context of personality research.

\section{The Descriptive Model of Adaptive Aspects of the Self}

If we consider self in terms of dynamic, conscious processes, the adaptive characteristics include a moderate level of self-awareness which is (a) nonruminative, (b) reflective, (c) motivated by curiosity, (d) relatively unbiased, and (e) focused mostly on inner states. Concerning self-knowledge, the adaptive characteristics include (f) integrated and (g) complex, containing (h) abstract and concrete self-beliefs which are similarly easily accessible, and are (i) aligned with an external reference or standard. Figure 1 is a graphical representation of the integration of the various aspect of the adaptive self-concept.

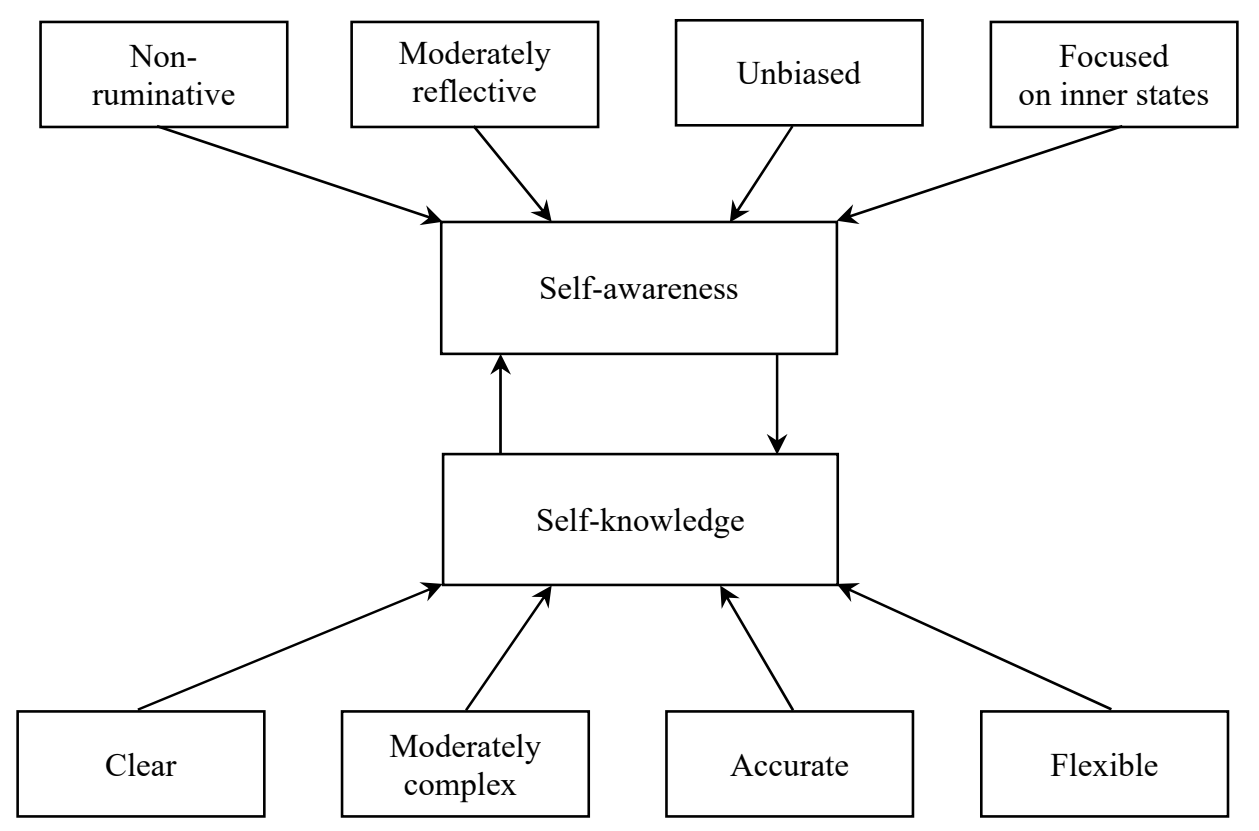

Figure 1. Descriptive Model of the Adaptive Self-Concept 
Self-awareness and self-knowledge are complementary, related aspects of the self (Leary \& Tangney, 2012). There is some empirical evidence that certain features of self-awareness - such as those included in our model-are related to specific aspects of self-knowledge. Non-ruminative self-awareness focused on inner states predicts clarity of self-concept (Campbell et al., 1996; Jankowski, 2008) whilst ruminative processing of self-relevant information inhibits cognitive flexibility and is associated with over-general autobiographical memory, which is characteristic of depression (Debeer et al., 2009). Similarly, self-rumination disturbs integrative processes, whereas self-reflection motivated by curiosity facilitates the development of a coherent self-concept (Ghorbani et al., 2008). Having contextually-adjusted awareness of one's inner states allows one to access detailed information which enables the development of rich and complex self-concept.

Thus, the adaptive self-concept can be understood as a set of characteristics, which fall into two related domains - self-awareness and self-knowledge. The five-factor theory (FFT; McCrae \& Costa, 1999) can be used to relate the model of the ASC to the broader field of personality research. FFT assumes that there are two central aspects of personality, stable basic tendencies and relatively malleable characteristic adaptations. We consider ASC to be the most important characteristic adaptation and assume that it is the product of both genetic and environmental influences. We suggest that the extent to which one's self is adaptive can be altered with conscious effort (e.g., psychotherapy). The ASC is an individual's most important adaptation, so it influences the effectiveness of functioning in other domains such as self-regulation and interpersonal relationships and thus affects growth and well-being.

\section{Determinants of the Adaptive Self-Concept}

\section{Basic Tendencies}

Concerning basic tendencies, neuroticism seems to be the most plausible determinant of ASC. Neuroticism predicts many aspects of self-concept. It is strongly related to self-concept clarity (e.g., Lavalle \& Campbell, 1995; Campbell et al., 1996), rumination (e.g., Trapnell \& Campbell, 1999; Hervás \& Vázquez, 2011) and unity of the self-system (Campbell et al., 2003). It also moderates the association between ideal-actual self-discrepancy and negative affect (Wasylkiv et al., 2010; Hong et al., 2013). Hervás and Vázquez (2011) showed that emotional 
overproduction, the tendency to experience many different negative emotions simultaneously - which is common among people with a ruminative style of thinking — is one of the mechanisms accounting for these associations.

\section{Environmental Influences}

The adaptive value of the self is also heavily influenced by social interactions (Harter, 2012). The quality of one's relationships with significant others shapes both content and the structure of one's self-concept. At least two well-documented theories have emphasized the importance of social, environmental factors for the development of adaptive aspects of the self-the attachment theory (Bowlby, 1982) and the self-determination theory (Deci \& Ryan, 2000). Attachment theory states that attachment style - how an individual approaches social interactions - is based on social experiences in infancy and childhood. The relationship between these early social experiences and attachment style in adulthood is mediated by mental models of the self. Individuals may see themselves as being worthy or unworthy of love and attention, depending on the nature of their early social experiences (Bowlby, 1982; Griffin \& Bartholomew, 1994). There is a large body of empirical evidence supporting the existence of a network of relationships linking interpersonal experiences, attachment styles and self-concept characteristics (e.g. Bacro, 2012; Procaccia et al., 2014; Tokar et al., 2003; Verschueren et al., 2012), particularly clarity, non-ruminative self-focus and authenticity (Gillath et al., 2010; Lanciano et al., 2012; Wu, 2009).

Self-determination theory (SDT) assumes that almost all forms of human behavior are mediated by the self, conceived as a psychological system consisting of self-related processes, beliefs, values, goals, etc. (Ryan et al., 2006). If the self-system is internally integrated, we can say that an individual has a true self, and having a true self is associated with well-being and the capacity for autonomous action. A self which lacks internal consistency or unity may be termed a false self; it manifests itself in contingent and maladaptive behavior. Whether an individual develops a true or false self depends on whether the influence of their significant others facilitates or disturbs their psychological growth. Parental support for a child enabling her to fulfil the fundamental human needs for autonomy, competence and relatedness will help the child to develop a true self. In contrast, a parental interaction style based on control is more likely to result in a child developing a false self, a more contingent and malleable self-image that results in maladaptive functioning (Assor et al., 2004). These basic tenets of SDT have 
received empirical support from research relating parenting styles to the unity of self-system (Lynch et al., 2009), compulsive over-investment (Assor \& Tal, 2012), identity style (Smits et al., 2010), and identity formation (Luyckx et al., 2009).

\section{CONCLUSIONS}

The main aim of this article was to propose a descriptive model of the ASC. It summarizes and synthesizes the aspects of the self that are crucial for successful adaptation. We have also discussed potential developmental factors of the ASC and related the model of ASC to the broader theory of personality.

Although it is grounded in an extensive review of the literature, the current status of the ASC model is rather "in progress." First, empirical verification of our proposals is necessary, particularly for the hypothesized causal relationships, as in the case of ASC antecedents. Second, future investigations should focus on important theoretical issues related to the conceptual status of the ASC. What is not clear for the moment is whether the ASC is a higher-order, latent factor that explains variation in lower-order factors related to self-concept structure and self-awareness, or an emergent phenomenon, which comes out when contributing features co-occur. We favor the latter interpretation, but further research is required to settle this issue.

\section{REFERENCES}

Assor, A., Roth, G., \& Deci, E. L. (2004). The emotional costs of perceived parents' conditional regard: A self-determination theory analysis. Journal of Personality, 72, 47-89.

Assor, A., \& Tal, K. (2012). When parents' affection depends on child's achievement: Parental conditional positive regard, self-aggrandizement, shame and coping in adolescents. Journal of Adolescence, 35, 249-260.

Bacro, F. (2011). Perceived attachment security to father, academic self-concept and school performance in language mastery. Journal of Child and Family Studies, 21, 992-1002.

Bargh, J. A., \& Chartrand, T. L. (1999). The unbearable automaticity of being. American Psychologist, 54, 462-479.

Bauer, J. J., \& Wayment, H. A. (2008). The psychology of the quiet ego. In H. A. Wayment \& J. J. Bauer (Eds.), Transcending self-interest: Psychological perspectives on the quiet ego (pp. 3-19). American Psychological Association Books.

Baumeister, R. F. (1991). Escaping the self. Basic Books. 
Bigler, M., Neimeyer, G. J., \& Brown, E. (2001). The divided self revisited: Effects of self-concept clarity and self-concept differentiation on psychological adjustment. Journal of Social and Clinical Psychology, 20, 396-415.

Block, J. (1961). Ego identity, role variability, and adjustment. Journal of Consulting Psychology, 25, 392-397.

Bowlby, J. (1982). Attachment and loss: Vol. 1. Attachment (2nd ed.). Basic Books.

Brown, K. W., \& Holt, M. P. (2011). Experiential processing and the integration of bright and dark sides of the human psyche. In K. Sheldon, T. Kashdan, \& M. Steger (Eds.), Designing the future of positive psychology: Taking stock and moving forward (pp. 147-159). Oxford: Oxford University Press.

Brycz, H., \& Karasiewicz, K. (2011). Metacognition and self-regulation: The Metacognitive Self Scale. Acta Neuropsychologica, 9, 263-498.

Burnkrant, R. E., \& T. J. Page, Jr. (1984). A modification of the Fenigstein, Scheier, and Buss Self Consciousness Scales. Journal of Personality Assessment, 48, 629-637.

Campbell, J. D., Assanand, S., \& Di Paula, A. (2003). The structure of the self-concept and its relation to psychological adjustment. Journal of Personality, 71, 115-140.

Campbell, J. D., Trapnell, P. D., Heine, S. J., Katz, I. M., Lavallee, L. F., \& Lehman, D. R. (1996). Self-concept clarity: Measurement, personality correlates, and cultural boundaries. Journal of Personality and Social Psychology, 70, 141-156.

Colvin, C. R., \& Block, J. (1994). Do positive illusions foster mental health? An examination of the Taylor and Brown formulation. Psychological Bulletin, 116, 3-20.

Colvin, C. R., Block, J., \& Funder, D. C. (1995). Overly positive self-evaluations and personality: Negative implications for mental health. Journal of Personality and Social Psychology, 68, $1152-1162$.

Conway, M. (2005). Memory and the self. Journal of Memory and Language, 53, 594-628.

Creed, A. T., \& Funder, D. C. (1998). The two faces of private self-consciousness: Self report, peer-report, and behavioral correlates. European Journal of Personality, 12, 411-431.

Crocker, J. (2002). The costs of seeking self-esteem. Journal of Social Issues, 58, 597-615.

Crocker, J., \& Park, L. E. (2004). The costly pursuit of self-esteem. Psychological Bulletin, 130, 392-414.

Debeer, E., Hermans, D., \& Raes, F. (2009). Associations between components of rumination and autobiographical memory specificity as measured by a Minimal Instructions Autobiographical Memory Test. Memory, 17, 892-903.

Deci, E. L., \& Ryan, R. M. (2000). The "what" and "why" of goal pursuits: Human needs and the self-determination of behavior. Psychological Inquiry, 11, 227-268.

Diehl, M., Hastings, C. T., \& Stanton, J. M. (2001). Self-concept differentiation across the adult life span. Psychology and Aging, 16, 643-654.

Donahue, E. M., Robins, R. W., Roberts, B. W., \& John, O. P. (1993). The divided self: Concurrent and longitudinal effects of psychological adjustment and social roles on self-concept differentiation. Journal of Personality and Social Psychology, 64, 834-846.

Duval, T. S., \& Wicklund, R. A. (1972). A theory of objective self-awareness. Academic Press.

Fenigstein, A. (2009). Private and public self-consciousness. In M. R. Leary \& R. H. Hoyle (Eds.), Handbook of individual differences in social behavior (pp. 495-511). Guilford Press.

Fenigstein, A., Scheier, M. F., \& Buss, A. H. (1975). Public and private self-consciousness: Assessment and theory. Journal of Consulting and Clinical Psychology, 43, 522-527. 
Ferguson, G., Hafen, C. A., \& Laursen, B. (2010). Adolescent psychological and academic adjustment as a function of discrepancies between actual and ideal self-perceptions. Journal of Youth and Adolescence, 39, 1485-1497.

Förster, J., Marguc, J., \& Gillebaart, M. (2010). Novelty categorization theory. Social and Personality Psychology Compass, 9, 736-755.

Freitas, A. L., Gollwitzer, P., \& Trope, Y. (2004). The influence of abstract and concrete mindsets on anticipating and guiding others' self-regulatory efforts. Journal of Experimental Social Psychology, 40, 739-752.

Ghorbani, N., Watson, P. J., \& Hargis, M. B. (2008). Integrative Self-Knowledge Scale: Correlations and incremental validity of a cross-cultural measure developed in Iran and the United States. The Journal of Psychology, 142, 395-412.

Gillath, O., Sesko, A. K., Shaver, P. R., \& Chun, S. D. (2010). Attachment, authenticity, and honesty: Dispositional and experimentally induced security can reduce self- and otherdeception. Journal of Personality and Social Psychology, 98, 841-855.

Gollwitzer, P. M. (1999). Implementation intentions: Strong effects of simple plans. American Psychologist, 54, 493-503.

Greenwald, A. G. (1980). The totalitarian ego: Fabrication and revision of personal history. American Psychologist, 35, 603-618.

Griffin, D., \& Bartholomew, K. (1994). Models of the self and other: Fundamental dimensions underlying measures of adult attachment. Journal of Personality and Social Psychology, 67, $430-445$.

Harrington, R., \& Loffredo, D. A. (2011). Insight, rumination, and self-reflection as predictors of well-being. The Journal of Psychology, 145, 39-57.

Harter, S. (2012). Emerging self-processes during childhood and adolescence. In M. R. Leary \& J. P. Tangney (Eds.), Handbook of self and identity (2nd ed., pp. 680-715). Guilford Press.

Heppner, W. L., Kernis, M. H., Lakey, C. E., Campbell, W. K., Goldman, B. M., Davis, P. J., \& Cascio, E. V. (2008). Mindfulness as a means of reducing aggressive behavior: Dispositional and situational evidence. Aggressive Behavior, 34, 486-496.

Hervás, G. Y., Vázquez, C. (2011). What else do you feel when you feel sad? Emotional overproduction, neuroticism and rumination. Emotion, 11, 881-895.

Higgins, E. T. (1987). Self-discrepancy: A theory relating self and affect. Psychological Review, 94, 319-340.

Hodgins, H. S., Weibust, K. S., Weinstein, N., Shiffman, S., Miller, A., Coombs, G., \& Adair, K. C. (2010). The cost of self-protection: Threat response and performance as a function of autonomous and controlled motivations. Personality and Social Psychology Bulletin, 36, 1101-1114.

Hodgins, H. S., Yacko, H., \& Gottlieb, E. (2006). Autonomy and nondefensiveness. Motivation and Emotion, 30, 283-293.

Hong, R. Y., Triyono, W., \& Ong, P. S. (2013). When being discrepant from one's ideal or ought selves hurts: The moderating role of neuroticism. European Journal of Personality, 27, 256-270.

Ingram, R. E. (1990). Self-focused attention in clinical disorders: Review and a conceptual modal. Psychological Bulletin, 107, 156-176.

Jankowski, T. (2008). Integrująca rola uważności w kształtowaniu koncepcji siebie [Mindfulness as an integrating factor for the self-concept structure]. Przeglad Psychologiczny, 51, 443-464. 
Kernis, M. H., \& Goldman, B. M. (2006). A multicomponent conceptualization of authenticity: Theory and research. Advances in Experimental Social Psychology, 38, 283-357.

Klein, S. B., Cosmides, L., Tooby, J., \& Chance, S. (2002). Decisions and the evolution of memory: Multiple systems, multiple functions. Psychological Review, 109, 306-329.

Knee, C. R., \& Zuckerman, M. (1998). A nondefensive personality: Autonomy and control as moderators of defensive coping and self-handicapping. Journal of Research in Personality, $32,115-130$.

Koch, E. J., \& Shepperd, J. (2004). Is self-complexity linked to better coping? A review of the literature. Journal of Personality, 72, 727-760.

Lakey, C. E., Kernis, M. H., Heppner, W. L., \& Lance, C. E. (2008). Individual differences in authenticity and mindfulness as predictors of verbal defensiveness. Journal of Research in Personality, 42, 230-238.

Lanciano, T., Curci, A., Kafetsios, K, Elia, L., \& Zammuner, V. L. (2012). Insecure attachment and dysfunctional rumination: The mediating role of emotional intelligence abilities. Personality and Individual Differences, 53, 753-758.

Langer, E. (1989). Mindfulness. Da Capo Books.

Langer, E., \& Moldoveanu, M. (2000). The construct of mindfulness. Journal of Social Issues, 56, $1-9$.

Lavallee, L. F., \& Campbell, J. D. (1995). The impact of personal goals on self-regulation processes elicited by daily negative events. Journal of Personality and Social Psychology, 69, 341-352.

Leary, M. R., Adams, C. E., \& Tate, E. B. (2006). Hypo-egoic self-regulation: Exercising self-control by diminishing the influence of the self. Journal of Personality, 74, 1803-1831.

Leary, M. R., Adams, C. E., \& Tate, E. B. (2010). Hypo-egoic self-regulation. In R. H. Hoyle (Ed.), Handbook of personality and self-regulation (pp. 474-497). Wiley-Blackwell.

Leary, M. R., \& Tangney, J. P. (2012). The self as an organizing construct in the behavioral and social sciences. In M. R. Leary \& J. P. Tangney (Eds.), Handbook of self and identity (2nd ed., pp. 1-18). Guilford.

Linville, P. W. (1985). Self-complexity and affective extremity: Don't put all your eggs in one cognitive basket. Social Cognition, 3, 94-120.

Linville, P. W. (1987). Self-complexity as a cognitive buffer against stress-related illness and depression. Journal of Personality and Social Psychology, 52, 663-676.

Lutz, C. J., \& Ross, S. R. (2003). Elaboration versus fragmentation: Distinguishing between self-complexity and self-concept differentiation. Journal of Social and Clinical Psychology, 22, 537-559.

Luyckx, K., Vansteenkiste, M., Goossens, L., \& Duriez, B. (2009). Basic need satisfaction and identity formation: Bridging self-determination theory and process-oriented identity research. Journal of Counseling Psychology, 56, 276-288.

Lynch, M. F., La Guardia, J. G., \& Ryan, R. M. (2009). On being yourself in different cultures: Ideal and actual self-concept, autonomy support, and well-being in China, Russia, and the United States. The Journal of Positive Psychology, 4, 290-304.

Lyubomirsky, S., \& Tkach, C. (2003). The consequences of dysphoric rumination. In C. Papageorgiou \& A. Wells (Eds.), Rumination: Nature, theory, and treatment of negative thinking in depression (pp. 21-41). John Wiley \& Sons. 
McAdams, D. P., Anyidoho, N. A., Brown, C., Huang, Y. T., Kaplan, B., \& Machado, M. A. (2004). Traits and stories: Links between dispositional and narrative features of personality. Journal of Personality, 72, 761-784.

McConnell, A. R. (2011). The multiple self-aspects framework: Self-concept representation and its implications. Personality and Social Psychology Review, 15, 3-27.

McCrae, R. R., \& Costa, P. T. (1999). A five-factor theory of personality. In L. A. Pervin \& O. P. John (Eds.), Handbook of personality (pp. 139-153). Guilford.

McKay, R. T., \& Dennett, D. C. (2009). The evolution of misbelief. The Behavioral and Brain Sciences, 32, 493-510.

McKenzie, K. S., \& Hoyle, R. H. (2008). The Self-Absorption Scale: Reliability and validity in non-clinical samples. Personality and Individual Differences, 45, 726-731.

Moore, S. A, \& Zoellner, L. A. (2007). Overgeneral autobiographical memory and traumatic events: An evaluative review. Psychological Bulletin, 133, 419-437.

Mor, N., \& Winquist, J. (2002). Self-focused attention and negative affect: A meta-analysis. Psychological Bulletin, 128, 638-662.

Niemiec, C. P., Brown, K. W., Kashdan, T. B., Cozzolino, P. J., Breen, W. E., Levesque-Bristol, C., \& Ryan, R. M. (2010). Being present in the face of existential threat: The role of trait mindfulness in reducing defensive responses to mortality salience. Journal of Personality and Social Psychology, 99, 344-365.

Oppenheimer, L. (2002). Self or selves? Theory and Psychology, 12, 97-128.

Procaccia, R., Veronese, G., \& Castiglioni, M. (2014). Self-characterization and attachment style: A creative method of investigating children's construing. Journal of Constructivist Psychology, 27, 174-193.

Pyszczynski, T., \& Greenberg, J. (1987). Self-regulatory perseveration and the depressive self-focusing style: A self-awareness theory of reactive depression. Psychological Bulletin, $102,122-138$.

Rafaeli-Mor, E., \& Steinberg, J. (2002). Self-complexity and well-being: A review and research synthesis. Personality and Social Psychology Review, 6, 31-58.

Robins, R. W., \& Beer, J. S. (2001). Positive illusions about the self: Short-term benefits and longterm costs. Journal of Personality and Social Psychology, 80, 340-352.

Ryan, R. M., \& Brown, K. W. (2003). Why we don't need self-esteem: On fundamental needs, contingent love, and mindfulness. Psychological Inquiry, 14, 71-76.

Ryan, R. M., Deci, E. L., Grolnick, W. S., \& La Guardia, J. G. (2006). The significance of autonomy and autonomy support in psychological development and psychopathology. In D. Cicchetti \& D. J. Cohen (Eds.), Developmental psychopathology: Theory and method (Vol. 1, pp. 795-849). John Wiley \& Sons.

Sedikides, C., \& Skowronski, J. J. (1997). The symbolic self in evolutionary context. Personality and Social Psychology Review, 1, 80-102.

Sheldon, K. M., Ryan, R. M., Rawsthorne, L. J., \& Ilardi, B. (1997). Trait self and true self: Crossrole variation in the Big-Five personality traits and its relations with psychological authenticity and subjective well-being. Journal of Personality and Social Psychology, 73, 1380-1393.

Showers, C. J., Abramson, L. Y., \& Hogan, M. E. (1998). The dynamic self: How the content and structure of the self-concept change with mood. Journal of Personality and Social Psychology, 75, 478-493. 
Showers, C. J., \& Zeigler-Hill, V. (2007). Compartmentalization and integration: The evaluative organization of contextualized selves. Journal of Personality, 75, 1181-1204.

Showers, C. J., \& Zeigler-Hill, V. (2012). Organization of self-knowledge: Features, functions, and flexibility. In M. R. Leary \& J. Tangney (Eds.), Handbook of self and identity (pp. 105-123). Guilford Press.

Silvia, P. J., \& Duval, T. S. (2001). Objective Self-Awareness Theory: Recent progress and enduring problems. Personality and Social Psychology Review, 5, 230-241.

Silvia, P. J., Eichstaedt, J., \& Phillips, A. G. (2005). Are rumination and reflection types of self-focused attention? Personality and Individual Differences, 38, 871-881.

Silvia, P. J., \& O’Brien, M. E. (2004). Self-awareness and constructive functioning: Revisiting "the human dilemma." Journal of Social and Clinical Psychology, 23, 475-489.

Smits, I., Soenens, B., Vansteenkiste, M., Luyckx, K., \& Goossens, L. (2010). Why do adolescents gather information or stick to parental norms? Examining autonomous and controlled motives behind adolescents' identity style. Journal of Youth and Adolescence, 39, 1343-1356.

Suedfeld, P. (2009). Integrative complexity. In M. Leary \& R. Hoyle (Eds.), Handbook of individual differences in social behavior (pp. 354-366). Guilford Press.

Sumner, J., Griffith, J. W., Mineka, S., Rekart, K. N., Zinbarg, R. E., \& Craske, M. G. (2011). Overgeneral autobiographical memory and chronic interpersonal stress as predictors of the course of depression in adolescents. Cognition and Emotion, 25, 183-192.

Swann, W. B., Jr., Stein-Seroussi, A., \& Giesler, B. (1992). Why people self-verify. Journal of Personality and Social Psychology, 62, 392-401.

Taylor, S. E., \& Brown, J. D. (1988). Illusion and well-being: A social psychological perspective on mental health. Psychological Bulletin, 103, 193-210.

Tokar, D. M., Withrow, J. R., Hall, R. J., \& Moradi, B. (2003). Psychological separation, attachment security, vocational self-concept crystallization, and career indecision: A structural equation analysis. Journal of Counseling Psychology, 50, 3-19.

Trapnell, P. D., \& Campbell, J. D. (1999). Private self-consciousness and the five-factor model of personality: Distinguishing rumination from reflection. Journal of Personality and Social Psychology, 76, 284-304.

Vallacher, R. R., \& Wegner, D. M. (1987). Action identification and human behavior. Psychological Review, 94, 3-15.

Vallacher, R. R., \& Wegner, D. M. (1989). Levels of personal agency: Individual variation in action identification. Journal of Personality and Social Psychology, 57, 660-671.

Verschueren, K., Doumen, S., \& Buyse, E. (2012). Relationships with mother, teacher, and peers: Unique and joint effects on young children's self-concept. Attachment and Human Development, 14, 233-248.

Wakslak, C. J., Nussbaum, S., Liberman, N., \& Trope, Y. (2008). Representations of the self in the near and distant future. Journal of Personality and Social Psychology, 95, 757-773.

Wasylkiw, L., Fabrigar, L. R., Rainboth, S., Reid, A. \& Steen, C. (2010). Neuroticism and the architecture of the self: Exploring neuroticism as a moderator of the impact of ideal self-discrepancies on emotion. Journal of Personality, 78, 471-492.

Wayment, H. A., Bauer, J. J., \& Sylaska, K. (2014). The quiet ego scale: Measuring the compassionate self-identity. Journal of Happiness Studies. https://doi.org/10.1007/s10902014-9546-z 
Wegner, D. M., \& Bargh, J. A. (1998). Control and automaticity in social life. In D. Gilbert, S. T. Fiske, \& G. Lindzey (Eds.), Handbook of social psychology (Vol. 1, pp. 446-496). McGraw-Hill.

Wegner, D. M., \& Vallacher, R. R. (1986). Action identification. In R. M. Sorrentino \& E. T. Higgins (Eds.), Handbook of motivation and cognition: Foundations of social behavior (pp. 550-582). Guilford.

Williams, J. M. G., Barnhofer, T., Crane, C., Herman, D., Raes, F., Watkins, E., \& Dalgleish, T. (2007). Autobiographical memory specificity and emotional disorder. Psychological Bulletin, $133,122-148$.

Wu, C. (2009). The relationship between attachment style and self-concept clarity: The mediation effect of self-esteem. Personality and Individual Differences, 47, 42-46.

Funding Information: This research was supported by a grant from the National Science Centre (NSC; 2015/19/B/HS6/02216). 